\title{
Using fecal sterols to assess dynamics of sewage input in sediments along a human-impacted river-estuary system in eastern China
}

\author{
Ding He ${ }^{a, *}$, Kai Zhang a , Jianhui Tang ${ }^{b}$, Xingqian Cui ${ }^{c}$, Yongge Sun ${ }^{\text {a }}$ \\ ${ }^{a}$ Institute of Environment \& Biogeochemistry (eBig), School of Earth Sciences, Zhejiang University, Hangzhou 310027, China \\ b Yantai Institute of Coastal Zone Research, CAS, Yantai, Shandong 264003, China \\ c Department of Earth, Atmospheric and Planetary Sciences, Massachusetts Institute of Technology, Cambridge, MA 02139, USA
}

\section{H I G H L I G H T S}

- Mutiple sedimentary sterols used for the sewage contamination assessment.

- Higher sewage input observed in the Xiaoqing River than the Laizhou Bay.

- Significant spatial instead of seasonal variation in fecal sterol concentrations observed.

- Seasonal variation of two fecal sterolbased ratios observed.

\section{A R T I C L E I N F O}

\section{Article history:}

Received 9 February 2018

Received in revised form 23 April 2018

Accepted 24 April 2018

Available online 2 May 2018

Editor: D. Barcelo

\section{Keywords:}

Fecal sterols

Sewage contamination

Biomarkers

Stable carbon isotopes

River-estuary system

\footnotetext{
* Corresponding author.

E-mail address: dinghe@zju.edu.cn (D. He).
}

G R A P H I C A L A B S T R A C T

The upper left panel showing the formation of $5 \alpha$ - and $5 \beta$-stanols is mainly modified from Bull et al., 2002.

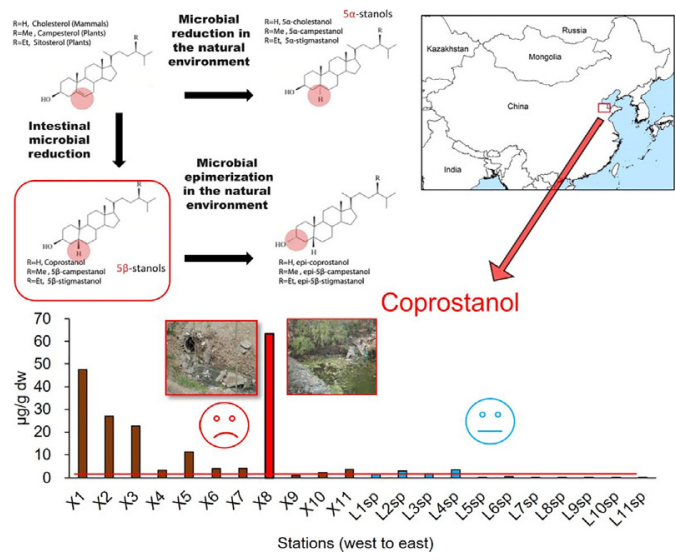

\begin{abstract}
A B S T R A C T
Sedimentary fecal sterols and other sterol biomarkers, combined with bulk total organic carbon (TOC) and its stable carbon isotope were applied to characterize the sewage contamination across a ca. $280 \mathrm{~km}$ transect from the Xiaoqing River to the Laizhou Bay, a typical river-estuary system subjected to extensive anthropogenic stress due to rapid regional urbanization and industrialization in eastern China. Two sampling events were performed in both spring and summer seasons in the Laizhou Bay adjacent to the Xiaoqing River in order to assess the potential seasonal variation. Fecal sterols such as coprostanol and epicoprostanol, which are typical indicators of anthropogenic sewage input, displayed high concentrations of up to $63.2 \mu \mathrm{g} \mathrm{g}^{-1}$ dry weight (dw) and $13.1 \mu \mathrm{g} \mathrm{g}^{-1} \mathrm{dw}$, respectively. Results suggested that most of the stations along the Xiaoqing River were severely contaminated by fecal inputs with a decreasing trend from the river to the estuary that was mainly explained by the increasing distance from the diffuse sewage sources and the gradual dilution by sea water. Although there was no significant difference in fecal sterol concentrations between spring and summer in the Laizhou Bay, suggestive of no significant difference in sewage abundance, significantly higher average epicoprostanol/coprostanol and lower coprostanol/epicoprostanol ratios were observed in spring than summer, indicative of different sewage sources (e.g., human vs. non-human). Seasonal discharge and land-runoff, air temperature related to microbial activity differences and different extend of animal manure irrigation during agricultural planting could be additional
\end{abstract}


reasons and need further investigation. Nevertheless, fecal sterol concentrations, distributions and diagnostic ratios should all be taken into consideration to better understand sewage inputs and source dynamics in riverestuary ecosystems.

(c) 2018 Elsevier B.V. All rights reserved.

\section{Introduction}

Anthropogenic interference in the form of domestic sewage discharge to rivers and coastal areas has caused severe environmental problems such as eutrophication, oxygen depletion and contamination (NBSC, 2012; Pan and Wang, 2012). Most of the coastal cities in China are characterized by a rapid industrialization and urbanization since the 1980s. Therefore, the assessment of anthropogenic contamination in coastal areas is of great interest for both the environment and human health, considering the high population density in these areas (e.g., Förstner, 2006; NBSC, 2012; Canuel and Hardison, 2016).

Sewage input, a major type of anthropogenic contamination that causes declining water quality in aquatic ecosystems, can be assessed using molecular markers (e.g., Bull et al., 2002; Carreira et al., 2004; Muniz et al., 2015; Derrien et al., 2017). Sterols, a common type of molecular markers, can be used to determine sources and fate of both anthropogenic (e.g., fecal input; e.g., Bull et al., 2002) and natural organic matter (OM; e.g., marine and terrigenous; Volkman, 2005) in environments. The phytosterols, including stigmasterol (stigmasta-5,22E-

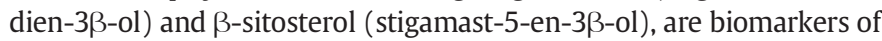
terrestrial organic matter (OM; Moreau et al., 2002). Brassicasterol (ergosta-5,22E-dien-3/-ol) is mainly produced by marine phytoplankton (Volkman, 1986); cholesterol (cholest-5-en-3ß-ol) is generally attributed to a wide diversity of phytoplankton and zooplankton (e.g., Volkman, 2005). These two sterols (brassicasterol and cholesterol) are widely used as biomarkers of aquatic OM. In contrast, the fecal sterols such as coprostanol ( $5 \beta$-cholestan-3 $\beta$-ol) and epicoprostanol ( $5 \beta$ cholestan-3 $\alpha$-ol) are usually considered to be derived from fecal pollution and urban wastewater inputs (Grimalt et al., 1990; González-Oreja and Saiz-Salinas, 1998; Bull et al., 2002; Carreira et al., 2004; Vane et al., 2010; Adnan et al., 2012; Abreu-Mota et al., 2014; Muniz et al., 2015; Rada et al., 2016). Coprostanol, a fecal sterol (5ß-stanol) detected predominantly in human feces, is preferentially produced in human guts by enzymatic reduction of cholesterol through anaerobic bacteria (Macdonald et al., 1983). Coprostanol comprises up to 60\% of total sterols in human feces (Leeming et al., 1996). Similar to other sterols that are commonly hydrophobic, coprostanol is generally associated with particulate matter in sewage and is finally incorporated and preserved in the bottom sediments (Bartlett, 1987). Previous studies proposed coprostanol concentrations above a certain level to be indicative of sewage contamination in aquatic sediments, although various thresholds were applied, such as $0.1,0.5$ or $0.7 \mu \mathrm{g} \mathrm{g}^{-1}$ dry weight (Grimalt et al., 1990; González-Oreja and Saiz-Salinas, 1998; Rada et al., 2016). However, Tse et al. (2014) suggested that coprostanol alone may not be sewage specific, since in situ anaerobic hydrogenation or microbial reduction processes can also produce coprostanol in sediments using cholesterol as the precursor (Fattore et al., 1996). Instead, a more robust assessment of sewage contamination can be conducted by investigating sterol-based ratios (e.g., Grimalt et al., 1990; Writer et al., 1995). For example, sterol-based diagnostic ratios have been applied to evaluate (i) whether the sewage was treated or not before being discharged (Mudge and Seguel, 1999), and (ii) the origins of the feces (human vs. animals; Venkatesan and Santiago, 1989; Leeming et al., 1996; Leeming et al., 1997; Bull et al., 2002).

Due to rapid urbanization in China, anthropogenic activities (e.g., sewage discharge) have induced severe contamination to the Chinese marginal seas, such as the Laizhou Bay (Zhang et al., 2009; Li et al., 2012). Laizhou Bay is a semi-closed system in the west of the Bohai Sea and receives water discharge from the Xiaoqing River and the Yellow River directly. The Xiaoqing River is the second largest river draining into the Laizhou Bay, only secondary to the Yellow River. In contrast with the Yellow River that is dominated by natural OM (Tao et al., 2015), the Xiaoqing River is severely polluted since the drainage basin of the Xiaoqing River is characterized by high-density population and extensive agricultural farming (Jiang et al., 2017). Although this system has been widely studied in terms of water chemistry and sediment chemistry (e.g., dissolved organic matter, heavy metals and persistent organic pollutants) (Ren et al., 2014; Wang et al., 2016; Jiang et al., 2017; Jiao et al., 2017), our current knowledge on fecal contamination, owing to the intensive urbanization in the watershed, is limited. Surface sediments in the river-estuary system provide excellent opportunities to evaluate levels of anthropogenic contamination and their influence on coastal ecosystems (e.g., Andrews et al., 1998). With high sedimentation rates of up to $9.4 \mathrm{~cm} / \mathrm{yr}$ (Li et al., 2012), fast accumulation of pollutants was detected in the Xiaoqing River mouth and Laizhou Bay (Zhang et al., 2009). The seasonal variations of the Xiaoqing River, in terms of water discharges, rain falls and hydrodynamic processes, could potentially affect the transport and deposition of sewage related OM (Liu et al., 2009; Gao, 2011; Yu et al., 2016).

In this study, surface sediments from spring and summer were collected along the Xiaoqing River-Laizhou Bay estuary system to (i) determine concentrations and sources of sedimentary sterols, (ii) assess sewage contamination levels in surface sediments, and (iii) examine spatial and seasonal influences on sedimentary fecal sterol distributions and possible controlling factors. Results from this study could potentially be relevant to sewage regulation and treatment in the future.

\section{Materials and methods}

\subsection{Description of study sites}

The Xiaoqing River is ca. $240 \mathrm{~km}$ and covers a drainage basin of ca. $2800 \mathrm{~km}^{2}$. It flows through numerous large cities, such as Jinan, Zibo, Binzhou, Dongying and Weifang, and is comprehensively utilized for controlling flood, irrigation, and shipping, etc. The Xiaoqing River empties into the Laizhou Bay in the Bohai Sea. The population sizes of Jinan, Zibo, Binzhou, Dongying and Weifang cities are approximately 7.23 million, 4.71 million, 3.8 million, 2.13 million, and 9.28 million, respectively. The average annual rainfall rate in the Xiaoqing River basin is ca. $620 \mathrm{~mm} / \mathrm{yr}$ with strong heterogeneity monthly. For example, July and August account for $>50 \%$ of the annual total rainfall (Gao, 2011). The average air temperature in spring and summer are $5{ }^{\circ} \mathrm{C}$ and $27^{\circ} \mathrm{C}$, respectively, based on data from a weather monitoring station in Jinan City (Gao, 2011). In recent years, the Xiaoqing River has undergone serious pollution due to rapid urbanization and industrialization. According to a survey in 2014 (Jinan Environmental Quality Report), 68.8\% of Jinan's industrial emission was discharged into the Xiaoqing River. There are approximately 20 key pollution sources distributed in the Xiaoqing River basin (Jinan Environmental Quality Report). Dissolved organic carbon (DOC) concentrations in the surface water of the Xiaoqing River mouth were from 5.1 to $10.1 \mathrm{mg} \mathrm{L}^{-1}$ and 5.1 to $55.9 \mathrm{mg} \mathrm{L}^{-1}$, and $\mathrm{NH}_{4}^{+}-\mathrm{N}$ concentrations from 2.5 to $9.3 \mathrm{mg} \mathrm{L}^{-1}$ and 2.5 to $9.3 \mathrm{mg} \mathrm{L}^{-1}$ in May and August of 2010, respectively (Cui et al., 2013), suggesting that the Xiaoqing River is heavily polluted. 


\subsection{Sample collection}

A total of 35 surface sediment samples (ca. 0-4 cm) were collected from the Xiaoqing River-Laizhou Bay in early April (spring) and late August (summer) of 2014. Sampling sites were selected based on an optimum spatial coverage of this system (Fig. 1; Fig. S1). Specifically, samples from X1 to X11 were only collected in spring and operationally defined as spatial end members representative of the Xiaoqing River (with surface water salinity $<4$ psu), whereas stations from L1 to L11, with salinity between 5.5 and $29.1 \mathrm{psu}$, were sampled in both spring (Lsp) and summer (Lsu) to identify potential seasonal variations. All the sediment samples were collected using a stainless-steel dredge sampler and immediately stored on ice during transportation to the laboratory and then freeze dried at $-50{ }^{\circ} \mathrm{C}$ before further analysis. During each sampling trip, water chemistry parameters, such as dissolved oxygen (DO) concentration, $\mathrm{pH}$, salinity, and redox potential, were measured using portable YSI ProPlus equipment (USA).

\subsection{Bulk parameter measurements}

Freeze dried sediment samples (ca. $1 \mathrm{~g}$ ) were homogenized and acidified using $0.1 \mathrm{M} \mathrm{HCl}$ solution to remove carbonates, rinsed with deionized water, and dried at $60{ }^{\circ} \mathrm{C}$. TOC measurements were performed using a Thermo Scientific FLASH2000 Series CNS Elemental Analyzer. Aliquots of the carbonate-free sediments were analyzed for $\delta^{13} C_{\text {org }}$ using a FLASH2000 Organic Elemental Analyzer coupled to a Thermo Fisher MAT-253 mass spectrometer. Samples were measured in duplicates and values were reported in average. A reference standard material (glycine) was analyzed every five measurements. The standard deviation of the replicate measurements was $\pm 0.2 \%$. Sediment grain size was measured following the method described in Fan et al. (2015).

\subsection{Extraction and fractionation}

Freeze dried sediments (ca. $10 \mathrm{~g}$ ) were Soxhlet extracted using mixed solvents of $100 \mathrm{ml}$ dichloromethane and $50 \mathrm{ml}$ methanol under dark conditions for 48 to $50 \mathrm{~h}$. The total extracts were concentrated to ca. $4 \mathrm{ml}$ by rotoevaporation followed by further dry-down under high purity $\mathrm{N}_{2}$ gas. The total extracts were separated on a silica gel column into aliphatic, aromatic and polar fractions using $n$-hexane, benzene and methanol/dichloromethane $(1: 1, \mathrm{v} / \mathrm{v})$, sequentially. Aliquots $(50$ $\mu \mathrm{l}$ ) of the polar fractions (containing sterols) were then evaporated to dryness under high purity $\mathrm{N}_{2}$ gas and derivatized at $60{ }^{\circ} \mathrm{C}$ for $2 \mathrm{~h}$ using ca. $50 \mu$ of BSTFA ( $N, O$ bis(trimethylsilyl)trifluoroacetamide) with $1 \%$ TMCS (trimethylchlorosilane). Finally, the derivatization products were dried under high purity $\mathrm{N}_{2}$ gas and redissolved in $n$-hexane for gas chromatography-mass spectrometry (GC-MS) analysis.

\subsection{GC-MS analysis}

The GC-MS system for biomarker analysis (Agilent 7890-5977MS) was equipped with an automatic split/splitless injector (autosampler AS-2912). The electron impact ionization (EI) mode was used. A DB5MS capillary column ( $60 \mathrm{~m}, 0.25 \mathrm{~mm}$ i.d.) was used, and the GC temperature was set under the following conditions: $60^{\circ} \mathrm{C}$ (held for $3 \mathrm{~min}$ ), ramping at $3{ }^{\circ} \mathrm{C} \mathrm{min}^{-1}$ to $300{ }^{\circ} \mathrm{C}$ (held for $30 \mathrm{~min}$ ). The injection was performed in splitless mode at $280{ }^{\circ} \mathrm{C}$. The mass spectrometer ion source was operated in electron impact (EI) mode at $70 \mathrm{eV}$. The GCMS interface and the ion source temperatures were set at $300{ }^{\circ} \mathrm{C}$ and $280^{\circ} \mathrm{C}$, respectively. Ultra-high purity helium was used as the carrier gas, and the flow rate was set to $1.2 \mathrm{~mL} \mathrm{~min}^{-1}$. Analysis was performed in total ion current (TIC) mode (50 to $600 \mathrm{~m} / \mathrm{z}$; Arcega-Cabrera et al., 2014). Individual sterol was identified based on relative retention times (e.g., Isobe et al., 2002; Derrien et al., 2011), the NIST 2008 library, literature and the interpretation of the ion fragmentation patterns. Deuterated $n$ hexatriaconataine was used as the internal standard (IS)

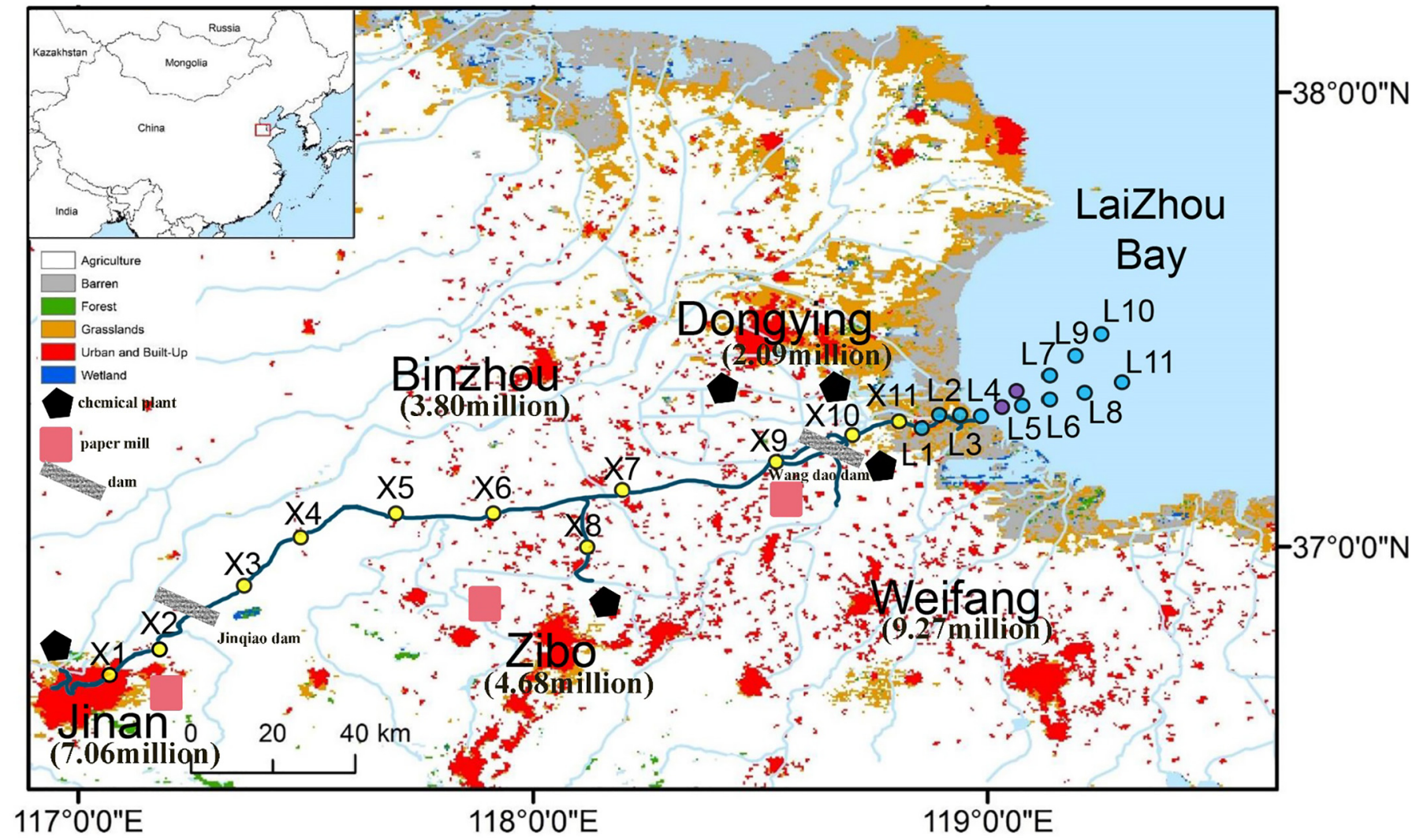

Fig. 1. Sampling map of the Xiaoqing River-Laizhou Bay, eastern China. 
(D'Anjou et al., 2012). Quantification was mainly based on Derrien et al. (2011), with some modifications. Briefly, a 5-point calibration curve ( 0.2 to $40 \mu \mathrm{g} \mathrm{ml}^{-1}$ ) was applied with a constant IS concentration at 10 $\mu \mathrm{g} \mathrm{m}{ }^{-1}$. Coprostanol, cholesterol and stigmasterol were quantified using the calibration curve of coprostanol, cholesterol and stigmasterol, respectively. Epicoprostanol, cholestanol ( $5 \alpha$-cholestan-3 $\alpha$-ol), epicholestanol ( $5 ß$-cholestan-3 $\alpha$-ol), stigmastanol (stgmastan-3ß-ol) and coprostanone (5ß-cholestan-3-one) were quantified using the calibration curve of coprostanol, whereas campesterol, sitosterol, brassicasterol, cholestenone and stigmastenone were quantified using the calibration curve of cholesterol, assuming same response factors (D'Anjou et al., 2012).

\subsection{Quality assurance/quality control}

A calibration of the GC-MS was conducted daily. A blank (pure nhexane) and external standard (coprostanol, stigmasterol, and cholesterol) were analyzed first. The sample analysis was then performed only after the correct instrument response was verified. Procedural blanks were also checked to ensure no peaks coeluted with the peaks of the target sterol compounds. The extraction recoveries of $>70 \%$ were considered acceptable. The precision for individual sterols was determined based on the analysis of a sediment sample in triplicate and standard deviation was found to be $<5.0 \%$ (He et al., 2014).

\subsection{Statistical analysis}

All statistical analyses were performed using the Origin 8.0 and $\mathrm{R}$ software. The Pearson correlation and principal component analysis
(PCA) were performed using a Vegan package. For the PCA, the major sterols detected were considered as the variables and the samples as the individuals.

\section{Results and discussion}

\subsection{Bulk parameters}

The $\mathrm{pH}$ of the surface water spanned a small range from 7.44 to 8.18 , 7.49 to 8.06 and 7.49 to 7.92 for the X, Lsp and Lsu samples, respectively, whereas the DO concentration varied considerably from 2.2 to $14.5 \mathrm{mg} \mathrm{l}^{-1}, 6.4$ to $9.5 \mathrm{mg} \mathrm{l}^{-1}$ and 5.8 to $12.5 \mathrm{mg} \mathrm{l}^{-1}$, respectively (Table 1). The redox potential of the surface water ranged from -27.2 to $198.0 \mathrm{mV}, 109.1$ to $213.2 \mathrm{mV}$ and 31.7 to $56.2 \mathrm{mV}$. In general, the upstream Xiaoqing River was characterized by low DO concentrations, while the Laizhou Bay was characterized by low redox potential in summer.

The sediments of the Xiaoqing River-Laizhou Bay were predominantly composed of silt (between $40.9 \%$ and $77.8 \%$; Table 1 ), denoting a region with relatively weak hydrodynamic conditions. The highest sand content (53.0\%) was observed at station L5 in spring, close to the Xiaoqing River mouth, suggesting this location was subject to intense waves and tidal currents. However, in general, no obvious spatial trend was observed for clay, silt or sand contents. The TOC contents ranged from $0.04 \%$ (station L6) to $4.01 \%$ (station X8; Table 1 ). This large range of TOC contents generally reflected different inputs of OM, hydrodynamic sorting processes, and possibly post-depositional biodegradation (Meyers, 2003).

Table 1

Bulk parameters of both the surface water and surface sediments at each sampling station.

\begin{tabular}{|c|c|c|c|c|c|c|c|c|c|c|}
\hline Station lists & Salinity $(\mathrm{psu})^{\mathrm{a}}$ & $\mathrm{pH}^{\mathrm{a}}$ & Dissolved oxygen $\left(\mathrm{mg} \mathrm{l}^{-1}\right)^{\mathrm{a}}$ & Redox potential $(\mathrm{mV})^{\mathrm{a}}$ & TOC (\%) & $\delta^{13} \mathrm{C}(\%)$ & Clay (\%) & Silt (\%) & Sand (\%) & Site description \\
\hline $\mathrm{X} 1$ & 0.6 & 7.44 & 2.5 & -27.2 & 3.13 & -25.3 & 12.9 & 69.6 & 17.5 & 1 \\
\hline $\mathrm{X} 2$ & 0.7 & 7.50 & 2.4 & 166.8 & 1.61 & -25.9 & 10.3 & 58.5 & 31.2 & 2 \\
\hline X3 & 0.7 & 7.54 & 2.2 & 155.3 & 1.60 & -25.5 & 23.3 & 61.7 & 15.1 & 3 \\
\hline $\mathrm{X} 4$ & 0.9 & 7.78 & 3.1 & -15.6 & 1.83 & -26.0 & 7.1 & 51.7 & 41.3 & \\
\hline $\mathrm{X} 5$ & 0.8 & 7.70 & 7.0 & 164.3 & 0.76 & -25.3 & 7.8 & 56.4 & 35.8 & 4 \\
\hline $\mathrm{X} 6$ & 1.6 & 7.56 & 6.1 & 116.4 & 1.09 & -25.3 & 12.6 & 66.7 & 20.8 & 5 \\
\hline X7 & 1.0 & 7.76 & 7.0 & 103.5 & 1.12 & -26.0 & 11.2 & 77.8 & 11.0 & 6 \\
\hline $\mathrm{X} 8$ & 2.4 & 7.47 & 6.0 & 150.5 & 4.01 & -26.7 & 7.7 & 65.0 & 27.2 & 7 \\
\hline X9 & 1.7 & 7.85 & 8.5 & 149.0 & 0.87 & -25.0 & 23.3 & 61.7 & 15.1 & 8 \\
\hline X10 & 3.6 & 8.18 & 14.5 & 198.0 & 0.66 & -26.3 & 10.5 & 61.0 & 28.5 & \\
\hline X11 & 3.2 & 7.58 & 10.8 & 148.9 & 0.74 & -26.5 & 10.6 & 58.1 & 31.3 & 9 \\
\hline L1sp & 9.2 & 7.49 & 6.4 & 111.4 & 0.57 & -26.2 & 7.7 & 47.3 & 45.0 & 10 \\
\hline L2sp & 5.5 & 7.67 & 7.8 & 170.4 & 0.66 & -25.9 & 9.0 & 55.4 & 35.6 & 11 \\
\hline L3sp & 10.2 & 7.61 & 7.1 & 149.7 & 0.50 & -25.4 & 13.3 & 60.0 & 26.8 & \\
\hline L4sp & 12.7 & 7.55 & 6.8 & 153.3 & 0.25 & -26.2 & 11.2 & 62.1 & 26.8 & \\
\hline L5sp & 25.0 & 7.50 & 6.8 & 109.1 & 0.38 & -24.6 & 6.1 & 40.9 & 53.0 & \\
\hline L6sp & 26.9 & 7.86 & 8.3 & 135.6 & 0.51 & -24.4 & 10.2 & 55.3 & 34.4 & \\
\hline L7sp & 27.2 & 7.93 & 9.5 & 213.2 & 0.22 & -23.5 & 16.4 & 66.7 & 16.9 & \\
\hline L8sp & 26.4 & 8.02 & 9.4 & 183.4 & 0.17 & -22.6 & 25.1 & 70.5 & 4.3 & \\
\hline L9sp & 27.2 & 7.97 & 8.8 & 147.3 & 0.09 & -23.1 & 17.4 & 66.8 & 15.8 & \\
\hline L10sp & 27.7 & 8.06 & 9.5 & 166.7 & 0.15 & -23.1 & 26.0 & 70.0 & 4.0 & \\
\hline L11sp & 27.7 & 7.98 & 8.4 & 150.2 & 0.15 & -23.1 & 16.1 & 69.3 & 14.7 & \\
\hline L1su & 14.4 & 7.49 & 5.8 & 46.8 & 0.68 & -25.5 & N.A. & N.A. & N.A. & \\
\hline L2su & 16.2 & 7.47 & 6.1 & 56.2 & 0.26 & -24.7 & N.A. & N.A. & N.A. & \\
\hline L3su & 18.1 & 7.51 & 4.8 & 41.5 & 0.38 & -25.5 & N.A. & N.A. & N.A. & \\
\hline L4su & 21.7 & 7.56 & 6.5 & 50.1 & 0.38 & -24.6 & N.A. & N.A. & N.A. & \\
\hline L5su & 23.8 & 7.64 & 9.1 & 31.7 & 0.17 & -24.1 & N.A. & N.A. & N.A. & \\
\hline L6su & 27.7 & 7.92 & 12.5 & 35.4 & 0.04 & -22.1 & N.A. & N.A. & N.A. & \\
\hline L7su & 28.6 & 7.88 & 9.0 & 44.4 & 0.17 & -22.9 & N.A. & N.A. & N.A. & \\
\hline L8su & 28.9 & 7.79 & 8.7 & 43.7 & 0.23 & -23.3 & N.A. & N.A. & N.A. & \\
\hline L9su & 28.5 & 7.85 & 8.6 & 34.9 & 0.16 & -23.0 & N.A. & N.A. & N.A. & \\
\hline L10su & 28.6 & 7.78 & 8.7 & 39.0 & 0.19 & -23.3 & N.A. & N.A. & N.A. & \\
\hline L11su & 29.1 & 7.85 & 3.6 & 37.7 & 0.18 & -23.6 & N.A. & N.A. & N.A. & \\
\hline L4-1su & 27.2 & 7.81 & 8.4 & 50.1 & 0.13 & -23.5 & N.A. & N.A. & N.A. & \\
\hline L4-2su & 25.3 & 7.65 & 8.4 & 52.1 & 0.16 & -22.5 & N.A. & N.A. & N.A. & \\
\hline
\end{tabular}

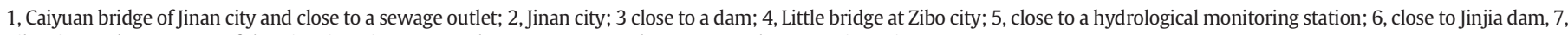
Zibo city; 8, downstream of the Xiaoqing River; 9, Yangkou town; 10 Yangkou Bay; 11, close to an ion mine.

a Parameters for surface water at each sampling station. N.A., data not available. 
The $\delta^{13} \mathrm{C}_{\text {org }}$ values in sediments ranged from $-26.7 \%$ to $-25.0 \%$, $-26.2 \%$ o to $-22.6 \%$ and $-25.5 \%$ o to $-22.1 \%$ o for the X, Lsp and Lsu samples, respectively, suggesting OM inputs from both terrestrial and marine sources (Pancost and Boot, 2004). The terrestrial OM is commonly characterized by lower $\delta^{13} \mathrm{C}_{\text {org }}$ values (e.g., - 27\%o), whereas the marine phytoplankton-derived $\mathrm{OM}$ has higher $\delta^{13} \mathrm{C}_{\mathrm{org}}$ values (e.g., -19\% to $-21 \%$; Fry and Sherr, 1989). A general decrease of TOC contents and an increase of $\delta^{13} \mathrm{C}_{\mathrm{org}}$ values were observed at stations with higher salinity (or spatially the Xiaoqing River to the Laizhou Bay; Fig. 2), indicative of a natural gradient where terrestrial OM generally decreased when gradually being dominated by marine environment.

\subsection{Sterol distributions and concentrations}

Human/animal and plant sterols were identified in all sediment samples, indicating that a variety of sources contributed to the composition of the sedimentary OM in this area (Table 2). The typical mass chromatograms of the sterols, stenones and stanones detected were presented in Fig. 3. The highest total sterol concentration (198.2 $\mu \mathrm{g}^{-1}$ ) was observed at station X8 with cholesterol being the dominant and followed by ß-sitosterol, campesterol, and stigmasterol.

Coprostanol was detected in all samples, with concentrations ranging from $0.03 \mu \mathrm{g} \mathrm{g}^{-1} \mathrm{dw}$ (station L6su) to $63.3 \mu \mathrm{g} \mathrm{g}^{-1} \mathrm{dw}$ (station X8), while epicoprostanol was from $0.02 \mu \mathrm{g} \mathrm{g}^{-1} \mathrm{dw}$ (station L6su) to 13.10 $\mu \mathrm{g} \mathrm{g}^{-1} \mathrm{dw}$ (station X1). The highest coprostanol concentration detected in this study is much higher than various other coastal areas worldwide, such as some tropical estuaries in Brazil (Martins et al., 2014; Carreira et al., 2015), the black sea (Readman et al., 2005), Kuwait's marine areas (Saeed et al., 2015) and the Macao Estuary close to Zhuhai and Macao cities, southern China (Peng et al., 2002) (Table S1). Coprostanol is a major component in omnivore feces (Leeming et al., 1996), but occurs at trace levels in plant species (Moreau et al., 2002). Epicoprostanol is commonly converted from coprostanol by intensive microbial activities and is usually detected in digested sludge samples (e.g., Mccalley et al., 1981). Therefore, the presence of epicoprostanol in all samples suggested that the sewage has been microbially degraded or partially digested (Mccalley et al., 1981; Mudge and Seguel, 1999; Bull et al., 2002). This result is reasonable when considering that there are some wastewater treatment systems in large cities in the Xiaoqing River watershed, such as Jinan and Zibo. Since sterols are hydrophobic, they preferentially adsorb onto fine suspended particles and are enriched in sediments with high TOC content (Writer et al., 1995; Froehner et al., 2009; Tolosa et al., 2014). The coprostanol concentrations correlated strongly with TOC contents ( $\mathrm{r}^{2}=0.87, P<0.01$; Fig. $\left.2 \mathrm{c}, \mathrm{d}\right)$, in agreement with a previous study in Cienfuegos Bay, Cuba (Tolosa et al., 2014). As expected, station X8, located at a sewage discharge site near Zibo city (Fig. S1), had the highest coprostanol concentration and TOC content (4.01\%). Station X1 near Jinan city displayed the second highest concentration of coprostanol, together with high TOC content (3.13\%), as well. Station X1 was severely affected by domestic sewage and manure waste from both Tianqiao and Lixia district of the Jinan City (Wang et al., 2011). Additionally, the strong correlation between coprostanol concentration and TOC content indicated that: (i) fecal sterols and the major part of OM had the similar source in this region, and (ii) fecal sterols could potentially track sewage input to this area. Strong anaerobic diagenetic processes were also seen at stations X8 and X1, as indicated by high concentrations of stenones and stanones (Table 2; Nishimura, 1982; de Leeuw et al., 1993; Rushdi et al., 2006). This finding was consistent with the general low redox potential and DO concentration at station X1.

As coprostanol is commonly associated with sewage discharge, its concentration has been used to indicate the level of sewage contamination (Grimalt et al., 1990; Takada and Eganhouse, 1998; González-Oreja and Saiz-Salinas, 1998; Rada et al., 2016). For example, Grimalt et al. (1990) suggested that coprostanol concentrations above $0.1 \mu \mathrm{g} \mathrm{g}^{-1}$ dw were indicative of sewage contamination, whereas 'significant' sewage contamination was defined as the level above $0.5 \mu \mathrm{g} \mathrm{g}^{-1} \mathrm{dw}$ (González-Oreja and Saiz-Salinas, 1998). Nevertheless, Rada et al. (2016) used $0.7 \mu \mathrm{g} \mathrm{g}^{-1} \mathrm{dw}$ as the threshold of sewage contamination. In our case, concentrations $>0.7 \mu \mathrm{g} \mathrm{g}^{-1} \mathrm{dw}$ were conservatively considered as sewage contamination. Based on this criterion, all X stations, 4 of 11 Lsp stations and 3 of 13 Lsu stations displayed obvious sewage contamination. In fact, most of the X stations were located near sewage sources from local cities or towns. In contrast, all other stations with lower concentrations of coprostanol were located in the Laizhou Bay, possibly due to seawater dilution. It clearly suggested that seawater

$$
\text { a) }
$$

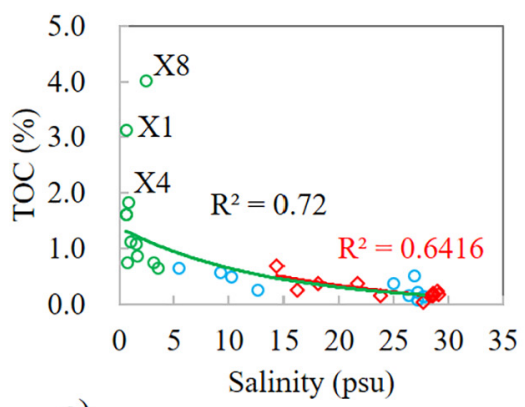

c)

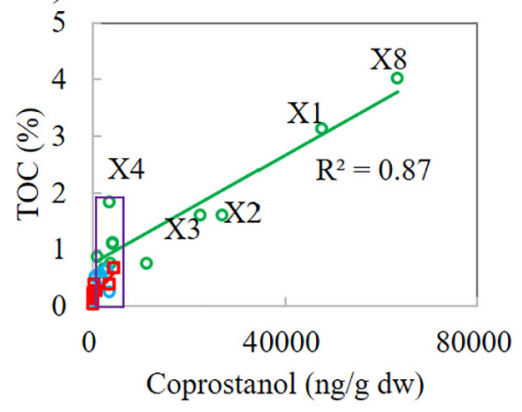

b)

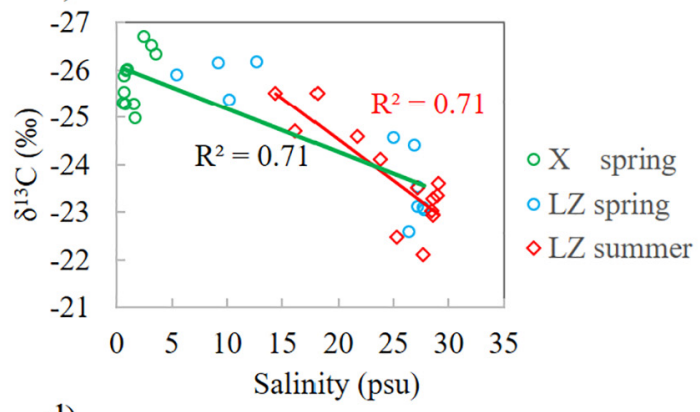

d)

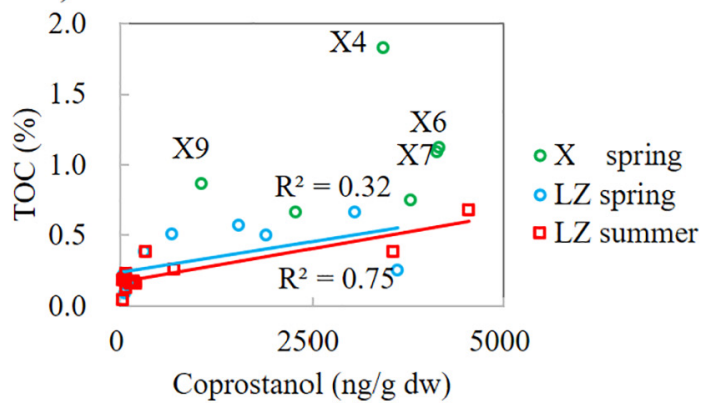

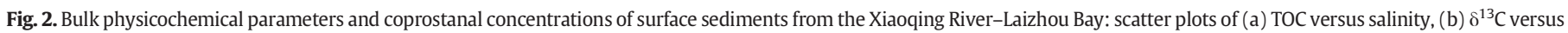
salinity, (c, d) TOC versus coprostanol concentrations. 
Table 2

Sterol biomarker for surface sediments from the Xiaoqing River-Laizhou Bay.

\begin{tabular}{|c|c|c|c|c|c|c|c|c|c|c|c|c|c|c|c|c|}
\hline $\begin{array}{l}\text { Station } \\
\text { lists }\end{array}$ & $\begin{array}{l}\text { Sum of } \\
\text { sterols }\end{array}$ & Coprostanol & 1 Epicoprostanol & Epicholestanol & Cholestanol & Cholesterol & Brassicasterol & 1 Coprostanone & Cholestanone & 24 Ethylcoprostanol & Cholestenone & Stigmasterol & Stigmastanol & Stigmastenone & Campesterol & Sitosterol \\
\hline $\mathrm{X} 1$ & 158.343 & 47.513 & 13.096 & 4.886 & 29.067 & 8.820 & 0.621 & 3.340 & 3.626 & 24.434 & 0.527 & 1.380 & 11.556 & 0.122 & 1.775 & 7.580 \\
\hline X2 & 126.275 & 27.003 & 5.530 & 1.304 & 8.360 & 37.411 & 1.845 & 4.655 & 2.946 & 12.341 & 0.701 & 4.192 & 3.399 & 0.231 & 5.149 & 11.208 \\
\hline X3 & 99.45 & 22.547 & 4.527 & 2.449 & 9.118 & 23.877 & 1.121 & 4.765 & 2.447 & 11.263 & 0.737 & 2.300 & 4.006 & 0.383 & 3.374 & 6.536 \\
\hline $\mathrm{X} 4$ & 18.606 & 3.436 & 0.524 & 0.200 & 1.479 & 5.588 & 0.357 & 0.496 & 0.371 & 2.224 & 0.136 & 0.976 & 0.849 & 0.075 & 0.976 & 0.919 \\
\hline X5 & 56.757 & 11.227 & 2.152 & 0.898 & 4.355 & 16.012 & 1.430 & 2.108 & 1.277 & 5.257 & 0.455 & 3.226 & 2.110 & 0.172 & 3.226 & 2.852 \\
\hline X6 & 32.937 & 4.131 & 1.167 & 0.377 & 2.225 & 10.530 & 1.138 & 0.846 & 0.697 & 2.332 & 0.345 & 3.631 & 0.849 & 0.075 & 3.226 & 1.368 \\
\hline $\mathrm{X} 7$ & 27.773 & 4.161 & 2.076 & 0.692 & 2.610 & 4.290 & 0.839 & 1.208 & 1.289 & 2.560 & 1.865 & 1.189 & 1.466 & 0.551 & 1.189 & 1.788 \\
\hline $\mathrm{X} 8$ & 195.865 & 63.262 & 7.299 & 3.433 & 6.063 & 21.764 & 2.442 & 7.884 & 6.087 & 13.162 & 46.769 & 2.650 & 1.835 & 3.668 & 4.318 & 5.229 \\
\hline X9 & 17.516 & 1.064 & 0.169 & 0.054 & 1.236 & 2.493 & 0.230 & 0.691 & 0.680 & 1.497 & 0.297 & 1.312 & 4.498 & 0.171 & 0.900 & 2.224 \\
\hline X10 & 22.446 & 2.301 & 0.285 & 0.095 & 2.173 & 4.034 & 0.937 & 0.317 & 0.509 & 1.657 & 0.352 & 2.310 & 2.001 & 0.331 & 1.854 & 3.290 \\
\hline X11 & 27.736 & 3.793 & 1.949 & 0.65 & 2.377 & 4.637 & 0.815 & 1.014 & 1.040 & 2.439 & 1.586 & 1.703 & 1.428 & 0.431 & 1.064 & 2.810 \\
\hline L1sp & 17.199 & 1.558 & 0.794 & 0.265 & 1.571 & 3.962 & 0.849 & 0.286 & 0.280 & 1.368 & 0.239 & 1.165 & 1.055 & 0.134 & 1.311 & 2.362 \\
\hline L2sp & 28.853 & 3.063 & 1.153 & 0.818 & 3.052 & 6.063 & 1.794 & 0.670 & 0.353 & 1.928 & 0.260 & 2.151 & 1.617 & 0.071 & 1.579 & 4.281 \\
\hline L3sp & 15.872 & 1.905 & 0.282 & 0.094 & 1.649 & 2.979 & 0.750 & 0.436 & 0.638 & 1.149 & 0.349 & 1.169 & 1.072 & 0.189 & 1.062 & 2.149 \\
\hline L4sp & 35.145 & 3.610 & 0.930 & 1.027 & 4.133 & 8.134 & 2.574 & 0.525 & 0.433 & 2.052 & 0.486 & 2.520 & 1.895 & 0.169 & 2.267 & 4.390 \\
\hline L5sp & 6.339 & 0.327 & 0.085 & 0.028 & 0.719 & 2.404 & 0.452 & $<\mathrm{LQ}$ & $<\mathrm{LQ}$ & 0.303 & $<\mathrm{LQ}$ & 0.462 & 0.410 & $<\mathrm{LQ}$ & 0.389 & 0.760 \\
\hline L6sp & 8.788 & 0.676 & 0.186 & 0.124 & 0.977 & 2.608 & 0.565 & 0.145 & 0.204 & 0.463 & 0.136 & 0.520 & 0.511 & 0.031 & 0.565 & 1.077 \\
\hline L7sp & 2.352 & 0.043 & 0.041 & 0.039 & 0.272 & 0.604 & 0.163 & $<\mathrm{LQ}$ & $<\mathrm{LQ}$ & $<\mathrm{LQ}$ & $<\mathrm{LQ}$ & 0.165 & 0.168 & $<\mathrm{LQ}$ & 0.163 & 0.694 \\
\hline L8sp & 5.465 & 0.144 & 0.035 & $<\mathrm{LQ}$ & 0.745 & 1.642 & 0.470 & $<\mathrm{LQ}$ & $<\mathrm{LQ}$ & 0.101 & $<\mathrm{LQ}$ & 0.264 & 0.689 & $<\mathrm{LQ}$ & 0.470 & 0.905 \\
\hline L9sp & 2.839 & 0.064 & 0.043 & 0.047 & 0.309 & 0.831 & 0.214 & 0.019 & 0.038 & $<\mathrm{LQ}$ & $<\mathrm{LQ}$ & 0.159 & 0.166 & $<\mathrm{LQ}$ & 0.214 & 0.735 \\
\hline L10sp & 6.602 & 0.114 & 0.077 & 0.075 & 0.578 & 1.850 & 0.427 & $<\mathrm{LQ}$ & $<\mathrm{LQ}$ & $<\mathrm{LQ}$ & $<\mathrm{LQ}$ & 0.435 & 0.505 & $<\mathrm{LQ}$ & 0.427 & 2.114 \\
\hline L11sp & 5.025 & 0.091 & 0.051 & 0.068 & 0.577 & 1.446 & 0.534 & 0.025 & 0.040 & 0.117 & $<\mathrm{LQ}$ & 0.269 & 0.295 & $<\mathrm{LQ}$ & 0.343 & 1.169 \\
\hline L1su & 64.035 & 4.553 & 2.169 & 1.855 & 9.336 & 10.154 & 2.025 & 1.785 & 1.437 & 4.118 & 1.189 & 4.601 & 5.675 & 0.724 & 4.845 & 9.569 \\
\hline L2su & 16.82 & 0.710 & 0.432 & 0.144 & 1.961 & 4.511 & 0.619 & 0.279 & 0.288 & 0.623 & 0.226 & 1.025 & 1.488 & 0.107 & 1.545 & 2.862 \\
\hline L3su & 18.885 & 0.331 & 0.153 & 0.085 & 0.785 & 8.827 & 1.198 & 0.261 & 0.229 & 0.380 & 0.152 & 1.404 & 0.522 & 0.052 & 2.318 & 2.188 \\
\hline L4su & 35.574 & 3.567 & 1.385 & 1.291 & 6.538 & 5.660 & 1.132 & 0.793 & 0.741 & 2.954 & 0.606 & 1.786 & 3.798 & 0.252 & 1.723 & 3.348 \\
\hline L5su & 4.678 & 0.178 & 0.053 & 0.014 & 0.470 & 1.776 & 0.576 & $<\mathrm{LQ}$ & $<\mathrm{LQ}$ & 0.124 & $<\mathrm{LQ}$ & 0.464 & 0.283 & $<\mathrm{LQ}$ & 0.225 & 0.515 \\
\hline L6su & 2.059 & 0.029 & 0.021 & $<\mathrm{LQ}$ & 0.222 & 1.148 & 0.065 & $<\mathrm{LQ}$ & $<\mathrm{LQ}$ & 0.020 & $<\mathrm{LQ}$ & 0.067 & 0.156 & $<\mathrm{LQ}$ & 0.061 & 0.270 \\
\hline L7su & 4.072 & 0.073 & 0.079 & 0.076 & 0.763 & 1.406 & 0.302 & 0.017 & 0.067 & $<\mathrm{LQ}$ & $<\mathrm{LQ}$ & 0.181 & 0.279 & $<\mathrm{LQ}$ & 0.299 & 0.530 \\
\hline L8su & 6.352 & 0.081 & 0.055 & 0.099 & 1.111 & 1.656 & 0.529 & 0.026 & 0.087 & 0.122 & $<\mathrm{LQ}$ & 0.292 & 0.810 & $<\mathrm{LQ}$ & 0.446 & 1.038 \\
\hline L9su & 10.504 & 0.21 & 0.162 & 0.264 & 0.210 & 4.340 & 0.900 & 0.056 & 0.125 & 0.216 & 0.173 & 0.484 & 0.831 & 0.059 & 0.902 & 1.572 \\
\hline L10su & 2.675 & 0.048 & 0.036 & 0.053 & 0.416 & 0.683 & 0.211 & 0.018 & 0.026 & $<\mathrm{LQ}$ & $<\mathrm{LQ}$ & 0.146 & 0.315 & $<\mathrm{LQ}$ & 0.201 & 0.522 \\
\hline L11su & 5.636 & 0.041 & 0.032 & 0.061 & 0.711 & 2.728 & 0.543 & 0.024 & 0.050 & $<\mathrm{LQ}$ & $<\mathrm{LQ}$ & 0.250 & 0.274 & $<\mathrm{LQ}$ & 0.326 & 0.596 \\
\hline L4-1su & 5.852 & 0.083 & 0.067 & 0.087 & 0.695 & 1.986 & 0.245 & $<\mathrm{LQ}$ & $<\mathrm{LQ}$ & $<\mathrm{LQ}$ & $<\mathrm{LQ}$ & 0.373 & $<\mathrm{LQ}$ & $<\mathrm{LQ}$ & 0.319 & 1.997 \\
\hline L4-2su & 7.784 & 0.139 & 0.087 & 0.084 & 0.638 & 3.582 & 0.645 & $<\mathrm{LQ}$ & $<\mathrm{LQ}$ & 0.108 & $<\mathrm{LQ}$ & 0.402 & 0.222 & $<\mathrm{LQ}$ & 0.595 & 1.282 \\
\hline
\end{tabular}

Note: all the units are $\mu \mathrm{g} \mathrm{g}^{-1}$ dry weight. 
a)
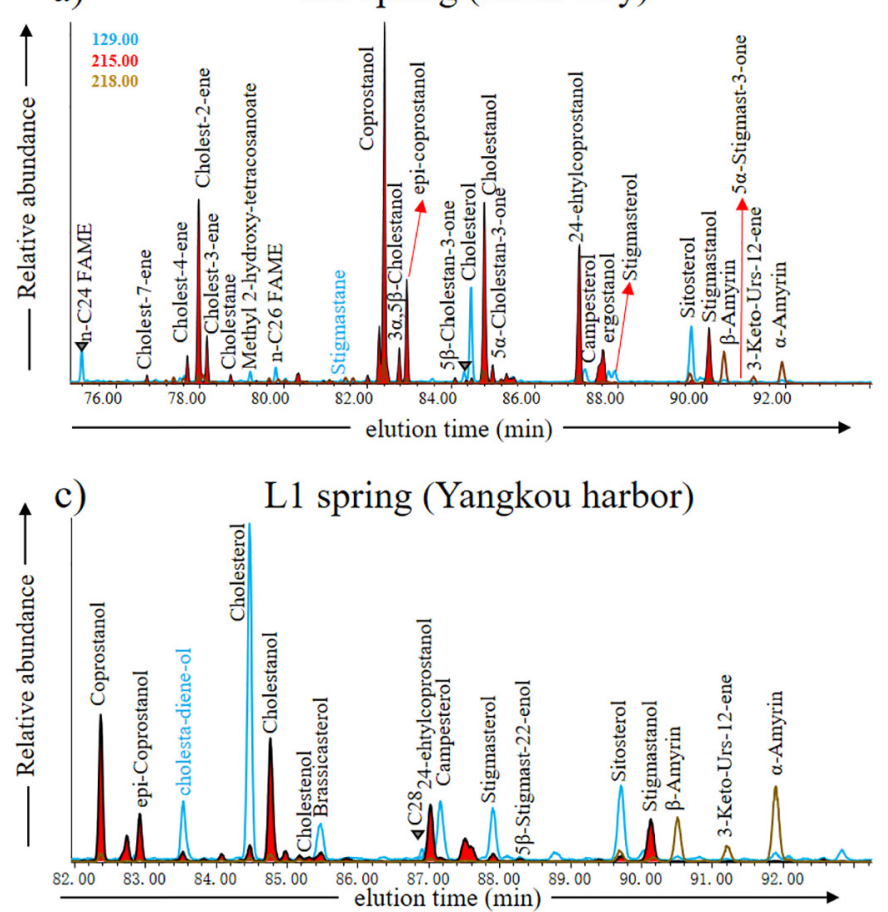

b)

L11 summer (Laizhou Bay)

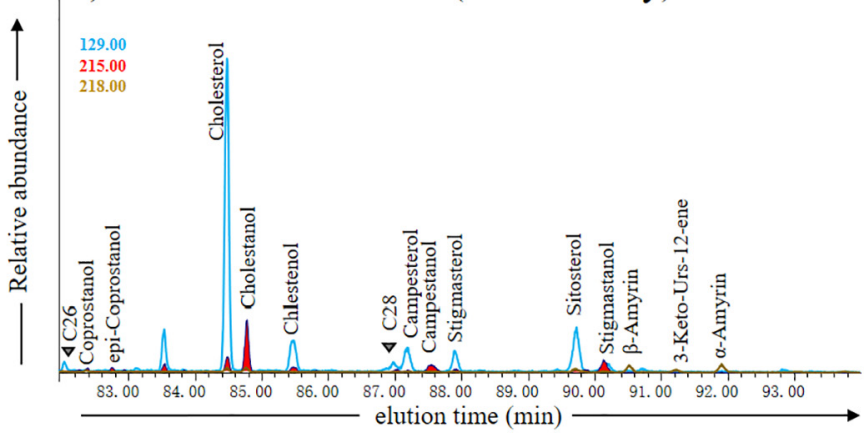

d)

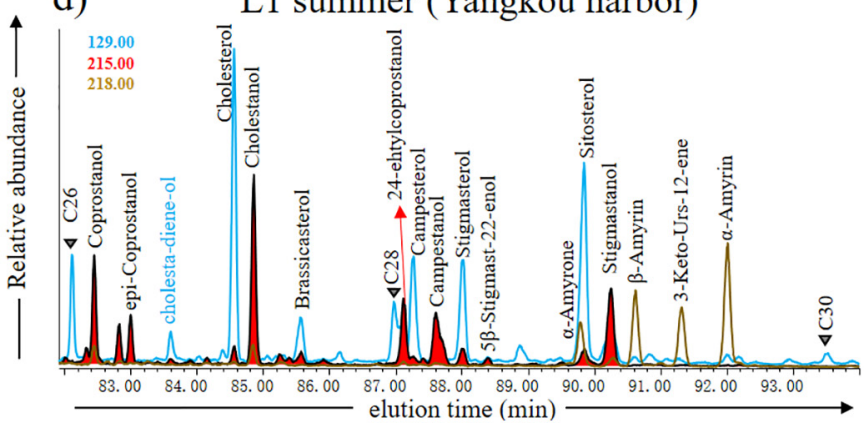

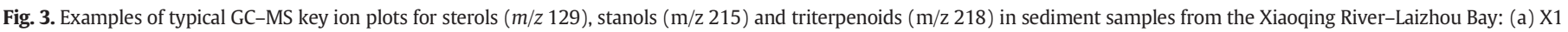
spring; (b) L11 summer; (c) L1 spring; (d) L1 summer. Triangles and circles denote $n$-alkanoic acids and $n$-alkanols, respectively.

dilution may be an important factor to consider in environments strongly dominated by marine organic carbon inputs.

\subsection{Evaluation of sterol ratios and sewage contamination}

Diagnostic ratios based on selected sterols were further calculated and applied to identify the presence of fecal contamination and differentiate sources of fecal matter (Table 3, Fig. S2; Writer et al., 1995; Fattore et al., 1996; Patton and Reeves, 1999; Carreira et al., 2004; Furtula et al., 2012 and references therein; Derrien et al., 2017 and references therein). In detail, a set of six ratios used in this study (Table 3) were classified into three groups to indicate sewage vs. nonsewage (R1 and R2), human vs. non-human sewage (R3, R4 and R5) and treatment vs. non-treatment sewage (R6).

The ratio of coprostanol/(coprostanol + cholestanol) (R1) was used to indicate the presence of sewage in aquatic ecosystems (e.g., Carreira et al., 2004; Rushdi et al., 2006; Martins et al., 2007). Based on R1, X2 to $\mathrm{X} 5$ and $\mathrm{X} 8$ stations appeared to be contaminated by sewage. In contrast, according to the coprostanol threshold value of $0.7 \mu \mathrm{g} \mathrm{g}^{-1} \mathrm{dw}$, all X stations (X1-11), L1sp to L4sp, L1su, L2su and L4su appeared to be contaminated by sewage. The coprostanol/(cholesterol + cholestanol) ratio (R2) is also used to elucidate the contribution from sewage vs. nonsewage sources with a criterion of R $2>0.06$ (Writer et al., 1995). At stations where these compounds were detected, R2 were higher than 0.06 for all X stations, 6 Lsp stations (L1sp to L6sp), and 4 Lsu stations (L1su, L2su, L4su and L5su), in agreement with high concentrations of coprostanol at these stations (Table 2) and the seawater dilution from the river to the Laizhou Bay spatially. Therefore, it is apparent, based on coprostanol concentrations and diagnostic ratios (R1 and R2), that the Xiaoqing River and the estuary region are severely contaminated by sewage.

The ratio of coprostanol/epicoprostanol (R3) is largely used to differentiate human sources and other mammalian feces (Fattore et al., 1996). R3 ranged from 0.92 to 8.67, with higher values at $X$ stations than Lsp and Lsu stations, pointing to a strong human waste input instead of other mammalian feces (Fattore et al., 1996). R3 can be further modified into (coprostanol + epicoprostanol) / (coprostanol + epicoprostanol + cholestanol) (R4) to compensate for any potential microbial conversion of coprostanol to epicoprostanol (Grimalt et al., 1990). Similar to R3, R4 has been applied as an indicator of human vs. non-human inputs with a criterion of $>0.7$ for human inputs (Bull et al., 2002). Based on this criterion, most of the X stations were confirmed to be dominated by human sewage input (see the picture of X8 in Fig. S1 as an example). Similarly, coprostanol/cholestanol (R5) ranged between 0.06 and 10.43 and higher ratios are generally associated with inputs from human sewage other than algae. The high ratios ( 0.86 to 10.43) of R5 found in most of the $X$ stations and selective spring stations in Laizhou Bay (e.g., L1sp to L4sp, L6sp, and L9su) implied a higher human sewage input than algal input (e.g., Shah et al., 2007), especially in spring. This is consistent with high coprostanol concentrations at most of these stations mentioned earlier. Additionally, the ratio of the $5 \beta$-phytostanols to the sum of the $5 \beta$-phytostanols, coprostanol and epicoprostanol $\left[5 \beta C_{28+29} /\left(5 \beta C_{28}+29+5 \beta C_{27}\right)\right]$ has been applied to assess the influence of livestock operations (Rushdi et al., 2006). This ratio spanned from 0 to 0.55 (averaged as $0.29 \pm$ 0.16 ), suggesting that the livestock waste was not the most dominant input in this ecosystem, which agreed with the dominance of human feces as suggested by R3, R4 and R5. Even though, the presence of herbivores sourced contaminants in this system is confirmed by the ratio of [(coprostanol) / (coprostanol +24 ethylcoprostanol)] that ranged between 0.40 and 0.69 (Bull et al., 2002). The overall low average value of $5 \beta C_{28+29} /\left(5 \beta C_{28}+29+5 \beta C_{27}\right)$ is in contrast to a study of Mesopotamian marshlands in Iraq, where higher values $(0.86 \pm 0.12$ to 0.91 \pm 0.13 ) were associated with the herbivore waste (Rushdi et al., 2006). Interestingly, the upper Xiaoqing River close to Jinan City and Zibo City (X1 to X8) were affected by abundant manure discharge and consisted $>58 \%$ of the total manure load from the entire watershed (Gao, 2011). However, from the diagnostic ratios (R3 to R5), the human fecal related sewage contamination from the cities should be more dominant that of the animal manure in the Xiaoqing River.

The ratio of epicoprostanol/coprostanol (R6), although reciprocal to $\mathrm{R} 3$, is considered to be indicative of the level of treatment or age of the 
Table 3

Sterol ratios indicative of sewage contamination.

\begin{tabular}{|c|c|c|c|c|c|c|}
\hline Station lists & $\mathrm{R} 1^{\mathrm{a}}$ & $\mathrm{R} 2^{\mathrm{a}}$ & $\mathrm{R}^{\mathrm{a}}$ & $\mathrm{R} 4^{\mathrm{a}}$ & $\mathrm{R}^{\mathrm{a}}$ & $\mathrm{R} 6^{\mathrm{a}}$ \\
\hline $\mathrm{X} 1$ & 0.62 & 1.25 & 3.63 & 0.68 & 1.63 & 0.28 \\
\hline $\mathrm{X} 2$ & 0.76 & 0.59 & 4.88 & 0.80 & 3.23 & 0.20 \\
\hline X3 & 0.71 & 0.68 & 4.98 & 0.75 & 2.47 & 0.20 \\
\hline $\mathrm{X} 4$ & 0.70 & 0.49 & 6.56 & 0.73 & 2.32 & 0.15 \\
\hline $\mathrm{X} 5$ & 0.72 & 0.55 & 5.22 & 0.75 & 2.58 & 0.19 \\
\hline X6 & 0.65 & 0.32 & 3.54 & 0.70 & 1.86 & 0.28 \\
\hline X7 & 0.61 & 0.60 & 2.00 & 0.70 & 1.59 & 0.50 \\
\hline $\mathrm{X} 8$ & 0.91 & 2.27 & 8.67 & 0.92 & 10.43 & 0.12 \\
\hline X9 & 0.46 & 0.29 & 6.31 & 0.50 & 0.86 & 0.16 \\
\hline X10 & 0.51 & 0.37 & 8.07 & 0.54 & 1.06 & 0.12 \\
\hline X11 & 0.61 & 0.54 & 1.95 & 0.71 & 1.60 & 0.51 \\
\hline L1sp & 0.50 & 0.28 & 1.96 & 0.60 & 0.99 & 0.51 \\
\hline L2sp & 0.50 & 0.34 & 2.66 & 0.58 & 1.00 & 0.38 \\
\hline L3sp & 0.54 & 0.41 & 6.76 & 0.57 & 1.16 & 0.15 \\
\hline L4sp & 0.47 & 0.29 & 3.88 & 0.52 & 0.87 & 0.26 \\
\hline L5sp & 0.31 & 0.10 & 3.83 & 0.36 & 0.45 & 0.26 \\
\hline L6sp & 0.41 & 0.19 & 3.64 & 0.47 & 0.69 & 0.27 \\
\hline L7sp & 0.14 & 0.05 & 1.06 & 0.23 & 0.16 & 0.94 \\
\hline L8sp & 0.16 & 0.06 & 4.18 & 0.19 & 0.19 & 0.24 \\
\hline L9sp & 0.17 & 0.06 & 1.47 & 0.26 & 0.21 & 0.68 \\
\hline L10sp & 0.16 & 0.05 & 1.47 & 0.25 & 0.20 & 0.68 \\
\hline L11sp & 0.14 & 0.04 & 1.76 & 0.20 & 0.16 & 0.57 \\
\hline L1su & 0.33 & 0.23 & 2.10 & 0.42 & 0.49 & 0.48 \\
\hline L2su & 0.27 & 0.11 & 1.64 & 0.37 & 0.36 & 0.61 \\
\hline L3su & 0.30 & 0.03 & 2.16 & 0.38 & 0.42 & 0.46 \\
\hline L4su & 0.35 & 0.29 & 2.58 & 0.43 & 0.55 & 0.39 \\
\hline L5su & 0.27 & 0.08 & 3.34 & 0.33 & 0.38 & 0.30 \\
\hline L6su & 0.12 & 0.02 & 1.37 & 0.18 & 0.13 & 0.73 \\
\hline L7su & 0.09 & 0.03 & 0.92 & 0.17 & 0.10 & 1.09 \\
\hline L8su & 0.07 & 0.03 & 1.47 & 0.11 & 0.07 & 0.68 \\
\hline L9su & 0.50 & 0.05 & 1.30 & 0.64 & 1.00 & 0.77 \\
\hline L10su & 0.10 & 0.04 & 1.33 & 0.17 & 0.11 & 0.75 \\
\hline L11su & 0.05 & 0.01 & 1.29 & 0.09 & 0.06 & 0.77 \\
\hline L4-1su & 0.11 & 0.03 & 1.24 & 0.18 & 0.12 & 0.81 \\
\hline L4-2su & 0.18 & 0.03 & 1.59 & 0.26 & 0.22 & 0.63 \\
\hline Lsp av. ${ }^{b}$ & 0.32 & 0.17 & 2.97 & 0.38 & 0.55 & 0.45 \\
\hline Lsu av. ${ }^{c}$ & 0.21 & 0.08 & 1.72 & 0.29 & 0.31 & 0.65 \\
\hline$P$ value $^{\mathrm{d}}$ & 0.11 & 0.07 & 0.04 & 0.16 & 0.10 & 0.04 \\
\hline
\end{tabular}

Bold fonts indicate the value exceed the traditional criteria.

a R1 Coprostanol / (coprostanol + cholestanol), indicator for sewage vs. biogenic source, $>0.7$ is the criteria (Grimalt et al., 1990); R2 Coprostanol / (cholesterol + cholestanol), indicator sewage vs. non-sewage, $>0.06$ is the criteria (Writer et al., 1995); R3 Coprostanol/Epicoprostanol, indicator for human vs. non-human, $>1.5$ is the criteria (Venkatesan and Santiago, 1989); R4 (Coprostanol + epicoprostanol) / (coprostanol + epicoprostanol + cholestanol), indicator of human vs. non-human, $>0.7$ is the criteria (Bull et al., 2002); R5 Coprostanol/cholestanol human vs. algae sterols, $>0.5$ is the criteria (Leeming et al., 1996); R6 Epicoprostanol/coprostanol, indicator for untreated vs. treated sewage, $<0.2$ is the criteria (Mudge and Seguel, 1999).

b Lsp av. denotes the average values of L1sp to L11sp.

c Lsu av. denotes the average value of L1su to L11su.

d $P$ value denotes significant Student's $t$-test comparing the average values of Lsp stations and Lsu stations.

fecal material (Mccalley et al., 1981; Mudge and Seguel, 1999; Venkatesan and Santiago, 1989). R6 ranged between 0.12 and 1.09, implying contributions from both untreated and treated sewage. Many $\mathrm{X}$ stations (X4, X5, X8 to X10) had $\mathrm{R} 6$ ratios lower than 0.2, suggestive of a substantial portion of the untreated sewage at these stations (Mudge and Seguel, 1999; Furtula et al., 2012). Overall, our results suggested that the sewage input in this region, although partially untreated, is dominated by human feces and is seconded by herbivores feces.

\subsection{Allocation of sewage contamination by principal component analysis}

The principal component analysis (PCA) has been shown to be a powerful tool assessing OM source, including the sewage contamination assessment (e.g., Derrien et al., 2012). Similar to other studies (Adnan et al., 2012; Frena et al., 2016; Speranza et al., 2018), PCA was performed using major sterols that were consistently detected (sterols that were $<0.5 \%$ abundance or not detected in partial samples were excluded), including coprostanol, epicoprostanol, cholestanol, cholesterol, brassicasterol, stigmasterol, stigmastanol, campesterol, and $\beta$ sitosterol. The relative abundance (\%) of each individual sterol was used as variables for PCA (Derrien et al., 2015). The first two components explained 67.6 (PC1) and 18.8\% (PC2) of the total variance, respectively (Fig. 4). Most of the compounds showed positive loadings along PC1 axis, with the exception of brassicasterol that had a negative loading. Along PC2, all the sewage indicators such as coprostanol and epicoprostanol had positive loadings, whereas the dominant biogenic sterols such as cholesterol, $\beta$-sitosterol, stigmasterol, campesterol and brassicasterol all displayed negative loadings. Therefore, PC1 seems to differentiate algal sources from terrestrial and anthropogenic sources, whereas PC2 seems to differentiate sterols (mainly precursors) from stanols (mainly by-products). Based on scores on PC1 and PC2, the X stations were generally separated from all other stations, whereas the Lsp stations were not separated from the Lsu stations, even though the Lsp stations had higher average PC1 and PC2 scores $(-0.34$ and -0.01 , respectively) than those of the Lsu stations ( -0.45 and -0.06 ; Fig. 4). With higher average PC1 and PC2 scores, most of the X stations showed contamination from sewage, which is consistent with fecal sterol concentrations and calculated diagnostic ratios (Tables 2, 3, Fig. S2). For instance, X1 and X8 had the highest PC1 and PC2 scores, consistent with positive loadings of fecal sterols (coprostanol and epicoprostanol) on PC1 and PC2. The stations located in the Xiaoqing River mouth (X9 to X11) or Laizhou Bay (L5 to L11) had significantly lower PC1 scores than the upstream X stations (X1 to X3), probably due to the dilution of sewage by seawater and/or the effects of marine currents at these stations. In addition, the Lsp and Lsu stations had lower PC1 scores than the X

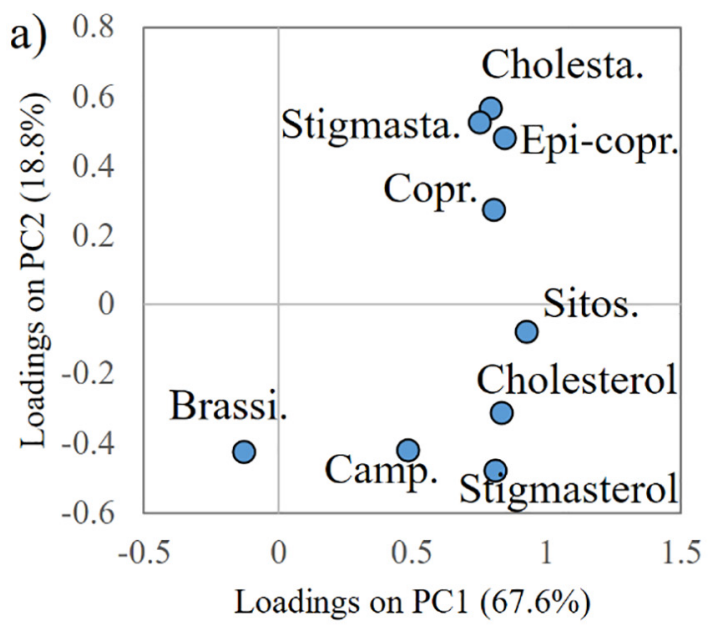

b)

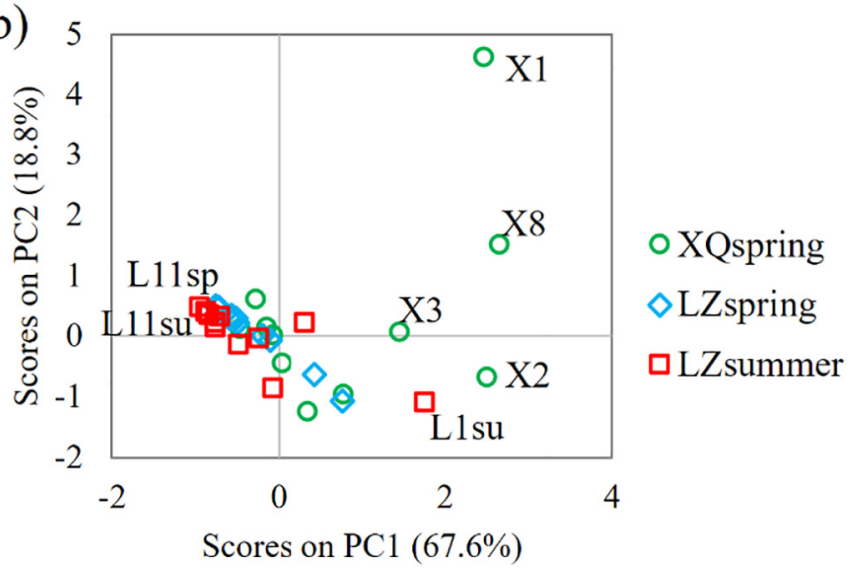

Fig. 4. Principal component analysis showing loadings and scores for two main components of sediment samples collected from the Xiaoqing River-Laizhou Bay. Copr. stands for coprostanol, Epicopr. epicoprostanol, Cholesta. Cholestanol, Choleste. Cholesterol, Stigma. Stigmasterol, Stigmasta. Stigmastanol, Camp. Campesterol, Sito. ß Sitosterol. 
stations, suggesting relatively stronger algal inputs in the estuarine stations than the river stations.

\subsection{Sewage input dynamics and their controlling factors}

On a broad scale, a strong spatial variation of sewage contamination was revealed by significantly higher coprostanol concentrations and distinctly different sterol-based ratios between the Xiaoqing River ( $\mathrm{X}$ stations) and the Laizhou Bay (Lsu and Lsp; Fig. S2). Furthermore, a clear spatial variation was observed along the Xiaoqing River, as supported by our PCA results and biomarker data. As mentioned earlier, the highest coprostanol concentrations and TOC contents were found at X8 and X1 stations. These two stations were highly associated with sewage discharge from large cities in Shandong province (Fig. S1), suggesting point source inputs may explain extraordinary patterns commonly observed along rivers.

The Xiaoqing River showed generally higher biomarker concentrations (e.g., coprostanol) in the upstream (X1-X8) than the downstream (X9-11). Although fluctuation has been observed among stations in each segment of the river, as displayed in biomarker data, the much higher sewage contamination seen in the upstream can largely be explained by human related fecal inputs due to the presence of many cities that host $>23$ million people, overall high people density ( $>699$ people per $\mathrm{km}^{2}$ ), and to a less extend by animal manure irrigation during agricultural planting (Zhang et al., 2008) in the upstream.

In addition to the spatial variation, a seasonal variation has been detected in the Laizhou Bay (L1 to L11) based on selected sterol-derived ratios (Fig. S2). For example, the average ratio of coprostanol/(cholesterol + cholestanol) in spring samples was more than twice of Lsu samples (avg. 0.17 vs $0.08 ; P=0.07$ ), indicative of relatively higher sewage input in spring than in summer. In addition, the mean ratio of R1 and R2 were significantly higher and lower in spring than in summer, respectively, suggesting relatively higher human derived and less treated sewage input in spring than in summer (Table 3, Fig. S2). Similarly, temporal variation of sewater contamination was found in an aquifer under the dry and rainy events, which is likely associated with sewage transported by surface runoff (Arcega-Cabrera et al., 2014). However, the seasonal variation is not observed in the PCA when considering the major sterols, which may be caused by the complex input of plant sterols (e.g., stigmasterol, campesterol), algal sterol (brassicasterol) and nonsource specific sterols (e.g., cholesterol). Furthermore, it should be careful that the seasonal variation observed based on diagnostic ratios could be caused by many other factors, such as river discharge and the consequent hydrodynamic sorting (Wang et al., 2014), temperature difference (about $20^{\circ} \mathrm{C}$ difference in average between spring and summer) and related microbial community structure and activities (Ylla et al., 2012). The latter one may likely cause preferential degradation of sterols or conversion reactions. Nevertheless, further research is required to explore the seasonal differences in this system.

\subsection{Further considerations}

There are some inconsistencies in specific sterol ratios in the Xiaoqing River-Laizhou Bay system (Table 3). For example, although epicoprostanol/coprostanol ratio and coprostanol/epicoprostanol ratio were significantly different between spring and summer, no significant difference was observed between these two seasons for the coprostanol/cholestanol ratio, the coprostanol/cholesterol ratio, the coprostanol/(cholestanol + cholesterol) ratio, and coprostanol concentrations. These inconsistencies could be caused by limited empirical observations and high variation in the estuarine hydrodynamics (e.g., Han et al., 2012; Canuel and Hardison, 2016), which requires further investigation. Therefore, the coupling of geochemical analysis with hydrogeological studies should be performed in the future for a better and comprehensive understanding of OM transport (Canuel et al., 2012). For instance, Wang et al. (2015) observed preferential absorption of biomarkers onto specific particles based on density fractionation in the Yangtze River Estuary and the adjacent shelf. In addition, when considering tremendous amount of sewage inputs as implied by fecal sterol concentrations, their diagnostic ratios and high deposition rates (Li et al., 2012), seasonal monitoring is recommended for evaluating environmental qualities and waste control strategy in this estuarine ecosystem. Especially, as stated in this study, point sources (X1 and X8) could be an important sewage contributor to the Xiaoqing River and require further regulation based on environmental policies and economic necessity.

With growing evidence of the adverse effects of emerging anthropogenic influences on estuarine ecosystems (Kennish, 1991; Paerl et al., 2006), it is necessary to combine multiple techniques and develop new approaches to accurately assess sewage contamination and sources (Canuel and Hardison, 2016). In addition, the usefulness of sterol ratios for sewage contamination evaluation and source tracking may also depend on factors other than seasonality and may even depend on estuary-specific processes. This highlights the necessity to deepen our understanding of the multiple processes influencing sterol ratios across a wide range of systems, which will strengthen the use of sterols as reliable, stable and meaningful indicators of fecal input on a broader scale.

\section{Conclusions}

The sewage input was determined for the first time in sediments collected from the Xiaoqing River-Laizhou Bay using sterol biomarkers. Source tracing of the sediments has revealed a widespread occurrence of human/animal and plant sterols. In general, the significant correlation observed between the coprostanol concentrations and TOC suggested that this biomarker reflects sewage inputs in this area. Sterol analysis is a reliable tool for sewage contamination assessment, but multiple sterol-derived ratios should be considered. Based on coprostanol concentrations, the diagnostic ratios between selected sterols and PCA analysis, most of the riverine stations and a few of the estuarine stations showed signatures of sewage contamination. With the high variability of environmental conditions in this estuary, a precise evaluation of seasonal variation is hard to assess at this point; however, the distinction between the spatial distributions of sterol biomarkers and different patterns of sterol ratios between seasons were observed. The spring season was characterized by relatively higher sewage input and less biogenic input.

This present study demonstrated the importance of organic geochemical studies in spatially different environments and different seasons; these studies are necessary for an integrated view of OM sources and transportation mechanisms. Additionally, environmental policies are required to reduce anthropogenic impacts and promote the health of this estuarine ecosystem. Furthermore, the results obtained in this study provided a reference example for future monitoring of other typical river-estuary systems, especially in coastal areas of eastern China.

\section{Acknowledgments}

D. He designed this study. All other authors joined in the sample preparation, data interpretation and discussion. The authors acknowledge Dr. J. Lin for drawing the sampling map. We also acknowledge Prof. A. Goonetilleke and three anonymous reviewers for their constructive comments. This work was supported by the National Science Foundation of China [41773098 to D. He; 41372131 to Y. Sun], the Scientific Planning Foundation of Guangdong Province [2015A070710016 to Y. Sun], the Chinese Academy of Sciences (KZZD-EW-14) and the "100" talent program of Zhejiang University [188020*194231701/008 and $188020-193810201 / 102$ to D. He].

\section{Appendix A. Supplementary data}

Supplementary data to this article can be found online at https://doi. org/10.1016/j.scitotenv.2018.04.314. 


\section{References}

Abreu-Mota, M.A., Barboza, C.A.M., Bícego, M.C., Martins, C.C., 2014. Sedimentary biomarkers along a contamination gradient in a human-impacted sub-estuary in southern Brazil: a multi-parameter approach based on spatial and seasonal variability. Chemosphere 103, 156-163.

Adnan, N.H., Zakaria, M.P., Juahir, H., Ali, M.M., 2012. Faecal sterols as sewage markers in the Langat River, Malaysia: integration of biomarker and multivariate statistical approaches. J. Environ. Sci. 24, 1600-1608.

Andrews, J.E., Greenaway, A.M., Dennis, P.F., 1998. Combined carbon isotope and C/N ratios as indicators of source and fate of organic matter in a poorly flushed, tropical estuary: hunts bay, kingston harbour, Jamaica. Estuar. Coast. Shelf Sci. 46, 743-756.

Arcega-Cabrera, F., Velázquez-Tavera, N., Fargher, L., Derrien, M., Noreña-Barroso, E., 2014. Fecal sterols, seasonal variability, and probable sources along the ring of cenotes, Yucatan, Mexico. J. Contam. Hydrol. 168, 41-49.

Bartlett, P.D., 1987. Degradation of coprostanol in an experimental system. Mar. Pollut. Bull. 18, 27-29.

Bull, I.D., Lockheart, M.J., Elhmmali, M.M., Roberts, D.J., Evershed, R.P., 2002. The origin of faeces by means of biomarkers detection. Environ. Int. 27, 647-654.

Canuel, E.A., Hardison, A.K., 2016. Sources, ages, and alteration of organic matter in estuaries. Annu. Rev. Mar. Sci. 8, 409-434.

Canuel, E.A., Cammer, S.S., Mcintosh, H.A., Pondell, C.R., 2012. Climate change impacts on the organic carbon cycle at the land-ocean interface. Annu. Rev. Earth Planet. Sci. 40, 685-711.

Carreira, R.S., Wagener, A.L.R., Readman, J.W., 2004. Sterols as markers of sewage contamination in a tropical urban estuary (Guanabara Bay, Brazil): space-time variations. Estuar. Coast. Shelf Sci. 60, 587-598.

Carreira, R.S., Albergaria-Barbosa, A.C.R., Arguelho, M.L., Garcia, C.A., 2015. Evidence of sewage input to inner shelf sediments in the NE coast of Brazil obtained by molecular markers distribution. Mar. Pollut. Bull. 90, 312-316.

Cui, Y., Zhang, L.J., Luo, X.X., Zhang, X., 2013. The evaluation of current water pollution and eutrophication status in the Xiaoqing River mouth. J. Ocean Univ. China 43, 60-66.

D'Anjou, R.M., Bradley, R.S., Balascio, N.L., Finkelstein, D.B., 2012. Climate impacts on human settlement and agricultural activities in northern Norway revealed through sediment biogeochemistry. Proc. Natl. Acad. Sci. U. S. A. 109, 20332-20337.

Derrien, M., Jardé, E., Gruau, G., Pierson-Wickmann, A.C., 2011. Extreme variability of steroids profils in cow faeces and pig slurries at regional scale: implications for the use of steroids to specify faecal pollution sources in waters. J. Agric. Food Chem. 59, 7294-7302.

Derrien, M., Jardé, E., Gruau, G., Pourcher, A.M., Gourmelon, M., Jadas-Hecart, A., Pierson Wickmann, A.C., 2012. Origin of fecal contamination in waters from contrasted areas: stanols as microbial source tracking markers. Water Res. 46, 4009-4016.

Derrien, M., Cabrera, F.A., Tavera, N.L.V., Manzano, C.A.K., Vizcaino, S.C., 2015. Sources and distribution of organic matter along the Ring of Cenotes, Yucatan, Mexico: Sterol markers and statistical approaches. Sci. Total Environ. 511, 223-229.

Derrien, M., Yang, L., Hur, J., 2017. Lipid biomarkers and spectroscopic indices for identifying organic matter sources in aquatic environments: a review. Water Res. 112, 58-71.

Fan, D., Shang, S., Cai, G., Tu, J., 2015. Distinction and grain-size characteristics of intertidal heterolithic deposits in the middle Qiantang estuary (east China Sea). Geo-Mar. Lett. $35,161-174$.

Fattore, E., Benfenati, E., Marelli, R., Cools, E., Fanelli, R., 1996. Sterols in sediment samples from Venice Lagoon, Italy. Chemosphere 33, 2383-2393.

Förstner, U., 2006. Contaminated Sediments: Lectures on Environmental Aspects of Particle-associated Chemicals in Aquatic Systems. vol. 21. Springer.

Frena, M., Bataglion, G.A., Tonietto, A.E., Eberlin, M.N., Alexandre, M.R., Madureira, L.A.S., 2016. Assessment of anthropogenic contamination with sterol markers in surface sediments of a tropical estuary Itajaí-Açu, Brazil. Sci. Total Environ. 544, 432-438.

Froehner, S., Martin, R.F., Errera, M.R., 2009. Assessment of fecal sterols in Barigui River sediments in Curitiba, Brazil. Environ. Monit. Assess. 157, 591-600.

Fry, B., Sherr, E.B., 1989. $\delta^{13} \mathrm{C}$ measurements as indicators of carbon flow in marine and freshwater ecosystems. Stable isotopes in ecological research. Springer, New York, NY, pp. 196-229.

Furtula, V., Liu, J., Chambers, P., Osachoff, H., Kennedy, C., Harkness, J., 2012. Sewage treatment plants efficiencies in removal of sterols and sterol ratios as indicators of fecal contamination sources. Water Air Soil Pollut. 223, 1017-1031.

Gao, Y.F., 2011. The Modelling Study of Agricultural Non-point Source for Xiaoqing he Watershed (Doctoral dissertation in Chinese, Chinese Academy of Agricultural Sciences).

González-Oreja, J.A., Saiz-Salinas, J.I., 1998. Short-term spatio-temporal changes in urban pollution by means of faecal sterols analysis. Mar. Pollut. Bull. 36, 868-875.

Grimalt, J.O., Fernández, P., Bayona, J.M., Albaigés, J., 1990. Assessment of fecal sterols and ketones as indicators of urban sewage inputs to coastal waters. Environ. Sci. Technol. 24, 357-363.

Han, D.M., Song, X.F., Currell, M.J., Tsujimura, M., 2012. Using chlorofluorocarbons (CFCs) and tritium to improve conceptual model of groundwater flow in the South Coast Aquifers of Laizhou Bay, China. Hydrol. Process. 26, 3614-3629.

He, D., Mead, R.N., Belicka, L., Pisani, O., Jaffé, R., 2014. Assessing source contributions to particulate organic matter in a subtropical estuary: a biomarker approach. Org. Geochem. 75, 129-139.

Isobe, K.O., Tarao, M., Zakaria, M.P., Chiem, N.H., Minh, L.Y., Takada, H., 2002. Quantitative application of fecal sterols using gas chromatography-mass spectrometry to investigate fecal pollution in tropical waters: western Malaysia and Mekong delta, Vietnam. Environ. Sci. Technol. 36, 4497-4507.

Jiang, T., Skyllberg, U., Björn, E., Green, N.W., Tang, J., Wang, D., Gao, J., Li, C., 2017. Characteristics of dissolved organic matter (DOM) and relationship with dissolved mercury in Xiaoqing River-Laizhou Bay estuary, Bohai Sea, China. Environ. Pollut. 223, 19-30.

Jiao, F., Ren, L., Wang, X., Liu, W., 2017. Pollution characteristics and potential ecologica risk assessment of metals in the sediments of Xiaoqing River, Jinan. Environ. Sci. Pollut. Res. 1-11.

Jinan Environmental Quality Reports, 1996-2014. The Environmental Protection Bureau of Jinan (in Chinese).

Kennish, M.J., 1991. Ecology of Estuaries: Anthropogenic Effects. vol. 1. CRC press.

Leeming, R., Ball, A., Ashbolt, N., Nichols, P., 1996. Using faecal sterols from humans and animals to distinguish faecal pollution in receiving waters. Water Res. 30, 2893-2900.

Leeming, R., Latham, V., Rayner, M., Nichols, P., 1997. Detecting and distinguishing sources of sewage pollution in Australian inland and coastal waters and sediments. ACS Symp. Ser. 671, 306-319.

de Leeuw, J.W., Cox, H.C., Bass, M., Peakman, T.M., van de Graaf, Bass, J.M.A., 1993. Relative stability of sedimentary rearranged sterenes as calculated by molecular mechanics: a key to unravel further steroid diagenesis. Org. Geochem. 20, 1297-1302.

Li, J., Hu, B.Q., Dou, Y.G., Zhao, J.T., Li, G.G., 2012. Modern sedimentation rate, budget and supply of the muddy deposits in the East China Seas. Geol. Rev. 58 (4), 745-756 (in Chinese).

Liu, A., Lang, Y., Xue, L., Liu, J., 2009. Ecological risk analysis of polycyclic aromatic hydrocarbons (PAHs) in surface sediments from Laizhou Bay. Environ. Monit. Assess. 159 (1), 429-436.

Macdonald, I.A., Bokkenheuser, V.D., Winter, J., McLernon, A.M., Mosbach, E.H., 1983. Degradation of steroids in the human gut. J. Lipid Res. 24, 675-700.

Martins, C.C., Fillmann, G., Montone, R.C., 2007. Natural and anthropogenic sterols inputs in surface sediments of Patos Lagoon, Brazil. J. Braz. Chem. Soc. 18, 106-115.

Martins, C.C., Cabral, A.C., Barbosa-Cintra, S.C., Dauner, A.L.L., Souza, F.M., 2014. An integrated evaluation of molecular marker indices and linear alkylbenzenes (LABs) to measure sewage input in a subtropical estuary (Babitonga Bay, Brazil). Environ. Pollut. 188, 71-80.

Mccalley, D.V., Cooke, M., Nickless, G., 1981. Effect of sewage treatment on faecal sterols. Water Res. 15, 1019-1025.

Meyers, P.A., 2003. Applications of organic geochemistry to paleolimnological reconstructions: a summary of examples from the Laurentian Great Lakes. Org. Geochem. 34 261-289.

Moreau, R.A., Whitaker, B.D., Kicks, K.B., 2002. Phytosterols, phytostanols and their conjugates in foods: structural diversity, quantitative analysis, and health-promoting uses. Prog. Lipid Res. 41, 457-500.

Mudge, S.M., Seguel, C.G., 1999. Organic contamination of San Vicente Bay, Chile. Mar Pollut. Bull. 38, 1011-1021.

Muniz, P., da Silva, D.A., Bícego, M.C., Bromberg, S., Pires-Vanin, A.M.S., 2015. Sewage contamination in a tropical coastal area (São Sebastião Channel, SP, Brazil). Mar. Pollut. Bull. 99, 292-300.

National Bureau of Statistics of China (NBSC), 2001-2012. China Energy Statistical Yearbook. China Statistics Press, Beijing.

Nishimura, M., 1982. 5 $\beta$-isomers of stanols and stanones as potential markers of sedimentary organic quality and depositional paleoenvironments. Geochim. Cosmochim. Acta 46, 423-432.

Paerl, H.W., Valdes, L.M., Peierls, B.L., Adolf, J.E., Harding Jr, L., 2006. Anthropogenic and climatic influences on the eutrophication of large estuarine ecosystems. Limnol. Oceanogr. 51, 448-462.

Pan, K., Wang, W.X., 2012. Trace metal contamination in estuarine and coastal environments in China. Sci. Total Environ. 421, 3-16.

Pancost, R.D., Boot, C.S., 2004. The palaeoclimatic utility of terrestrial biomarkers in marine sediments. Mar. Chem. 92, 239-261.

Patton, D., Reeves, A.D., 1999. Sterol concentrations and temporal variations on the north shore mudflats of the firth of Tay, Scotland. Mar. Pollut. Bull. 38, 613-618.

Peng, X., Zhang, G., Mai, B., Min, Y., Wang, Z., 2002. Spatial and temporal trend of sewage pollution indicated by coprostanol in Macao Estuary, southern China. Mar. Pollut. Bull. 45, 295-299.

Rada, J.P.A., Duarte, A.C., Pato, P., Cachada, A., Carreira, R.S., 2016. Sewage contamination of sediments from two Portuguese Atlantic coastal systems, revealed by fecal sterols. Mar. Pollut. Bull. 103, 319-324.

Readman, J.W., Fillmann, G., Tolosa, I., Bartocci, J., Mee, L.D., 2005. The use of steroid markers to assess sewage contamination of the Black Sea. Mar. Pollut. Bull. 50, 310-318.

Ren, L., Cui, E., Sun, H., 2014. Temporal and spatial variations in the relationship between urbanization and water quality. Environ. Sci. Pollut. Res. 21, 13646-13655.

Rushdi, A.I., DouAbul, A.A., Mohammed, S.S., Simoneit, B.R.T., 2006. Compositions and sources of extractable organic matter in Mesopotamian marshland surface sediments of Iraq: II. Polar compounds. Environ. Geol. 50, 1171-1181.

Saeed, T., Al-Shimmari, F., Al-Mutairi, A., Abdullah, H., 2015. Spatial assessment of the sewage contamination of Kuwait's marine areas. Mar. Pollut. Bull. 94, 307-317.

Shah, V.G., Dunstan, R.H., Geary, P.M., Coombes, P., Roberts, T.K., Von Nagy-Felsobuki, E., 2007. Evaluation potential applications of feacal sterols in distinguishing sources of faecal contamination from mixed faecal samples. Water Res. 41, 3691-3700.

Speranza, E.D., Colombo, M., Skorupka, C.N., Colombo, J.C., 2018. Early diagenetic alterations of sterol biomarkers during particle settling and burial in polluted and pristine areas of the Rio de la Plata Basin. Org. Geochem. 117, 1-11.

Takada, H., Eganhouse, R.P., 1998. Molecular markers of anthropogenic waste. In: Meyers, R.A. (Ed.), Encyclopedia of Environmental Analysis and Remediation. John Wiley and Sons, New York, pp. 2883-2940.

Tao, S., Eglinton, T.I., Montluçon, D.B., Mcintyre, C., Zhao, M., 2015. Pre-aged soil organic carbon as a major component of the Yellow River suspended load: regional significance and global relevance. Earth Planet. Sci. Lett. 414, 77-86.

Tolosa, I., Mesa, M., Alonso-Hernandez, C.M., 2014. Steroid markers to assess sewage and other sources of organic contaminants in surface sediments of Cienfuegos Bay, Cuba. Mar. Pollut. Bull. 86, 84-90. 
Tse, T.J., Codling, G., Jones, P.D., Thoms, K., Liber, K., Giesy, J.P., Doig, L.E., 2014 Reconstructing long-term trends in municipal sewage discharge into a small lake in northern Manitoba, Canada. Chemosphere 103, 299-305.

Vane, C.H., Kim, A.W., McGowan, S., Leng, M.J., Heaton, T.H.E., Kendrick, C.P., Coombs, P. Yang, H., Swann, G.E.A., 2010. Sedimentary records of sewage pollution using faecal markers in contrasting pen-urban shallow lakes. Sci. Total Environ. 409, 345-356.

Venkatesan, M.I., Santiago, C.A., 1989. Sterols in ocean sediments: novel tracers to examine habitats of cetaceans, pinnipeds, penguins and humans. Mar. Biol. 102, 431-437.

Volkman, J.K., 1986. A review of sterol markers for marine and terrigenous organic matter. Org. Geochem. 9, 83-99.

Volkman, J.K., 2005. Sterols and other triterpenoids: source specificity and evolution of biosynthetic pathways. Org. Geochem. 36, 139-159.

Wang, L.G., Li, H., Wang, Y.C., Qiu, J.J., 2011. Changes in livestock operation systems and their contributions to manure nitrogen pollution loading in Xiaoqinghe watershed, China. J. Agro-Environ. Sci. 5, 986-992 (in Chinese).

Wang, P., Lu, Y., Wang, T., Fu, Y., Zhu, Z., Liu, S., Xie, S., Xiao, Y., Giesy, J.P., 2014. Occurrence and transport of 17 perfluoroalkyl acids in 12 coastal rivers in south Bohai coastal region of China with concentrated fluoropolymer facilities. Environ. Pollut. 190, $115-122$.

Wang, J., Yao, P., Bianchi, T.S., Li, D., Zhao, B., Cui, X., Pan, H.H., Zhang, T.T., Yu, Z., 2015. The effect of particle density on the sources, distribution, and degradation of sedimentary organic carbon in the Changjiang Estuary and adjacent shelf. Chem. Geol. 402, 52-67.
Wang, P., Lu, Y., Wang, T., Meng, J., Li, Q., Zhu, Z., Sun, Y., Wang, R., Giesy, J.P., 2016. Shifts in production of perfluoroalkyl acids affect emissions and concentrations in the environment of the Xiaoqing River basin, China. J. Hazard. Mater. 307, 55-63.

Writer, J.H., Leenheer, J.A., Barber, L.B., Amy, G.L., Chapra, S.C., 1995. Sewage contamination in the upper Mississippi River as measured by the fecal sterol, coprostanol. Water Res. 29, 1427-1436.

Ylla, I., Romaní, A.M., Sabater, S., 2012. Labile and recalcitrant organic matter utilization by river biofilm under increasing water temperature. Microb. Ecol. 64, 593-604.

Yu, W., Liu, R., Xu, F., Men, C., Shen, Z., 2016. Identifications and seasonal variations of sources of polycyclic aromatic hydrocarbons (PAHs) in the Yangtze River Estuary, China. Mar. Pollut. Bull. 104, 347-354.

Zhang, Y.L., Dai, J.L., Wang, R.Q., Zhang, J., 2008. Effects of long-term sewage irrigation on agricultural soil microbial structural and functional characterizations in Shandong, China. Eur. J. Soil Biol. 44, 84-91.

Zhang, P., Song, J.M., Yuan, H.M., 2009. Persistent organic pollutant residues in the sediments and mollusks from the Bohai Sea coastal areas, North China: an overview. Environ. Int. 35, 632-646. 